TITLE:

\title{
Female Reproductive Seasonality and Male Influxes in Wild Mandrills (Mandrillus sphinx)
}

\section{AUTHOR(S):}

Hongo, Shun; Nakashima, Yoshihiro; AkomoOkoue, Etienne François; Mindonga-Nguelet, Fred Loïque

\section{CITATION:}

Hongo, Shun ...[et al]. Female Reproductive Seasonality and Male Influxes in Wild

Mandrills (Mandrillus sphinx). International Journal of Primatology 2016, 37(3): 416-437

\section{ISSUE DATE:}

2016-06

URL:

http://hdl.handle.net/2433/227216

\section{RIGHT:}

The final publication is available at Springer via https://doi.org/10.1007/s10764-016-9909-x.; The full-text file will be made open to the public on 01 June 2017 in accordance with publisher's 'Terms and Conditions for Self-Archiving'.; の論文は出版社版でありません。引用の際には出版社版をご確認ご利用ください。; This is not the published version Please cite only the published version. 
1 Female Reproductive Seasonality and Male Influxes in Wild Mandrills (Mandrillus sphinx)

2 Short running title: Mandrill Reproductive Seasonality and Male Influxes

3

$5 \quad$ Nguelet

6 Japan

Authors' institutional affiliations

\section{S. Hongo, Y. Nakashima, E. F. Akomo-Okoue}

Laboratory of Human Evolution Studies, Department of Zoology, Kyoto University, KitashirakawaOiwakecho, Sakyo-ku, Kyoto 606-8502, Japan

\section{Y. Nakashima}

College of Bioresource Science, Nihon University, 1866 Kameino, Fujisawa, Kanagawa 252-0880,

\section{E. F. Akomo-Okoue, F. L. Mindonga-Nguelet}

Institut de Recherche en Écologie Tropicale (IRET/CENAREST), BP 13354, Libreville, Gabon

\section{F. L. Mindonga-Nguelet}

Faculté des Sciences, Université des Sciences et Techniques de Masuku, BP 901, Franceville, Gabon

\section{Author for correspondence}

\section{Shun Hongo}

Laboratory of Human Evolution Studies, Department of Zoology, Kyoto University, Kitashirakawa-

Oiwakecho, Sakyo-ku, Kyoto-shi, Kyoto, 606-8502, Japan

Telephone: $+81-75-753-4085$

E-mail: hongo@jinrui.zool.kyoto-u.ac.jp 


\section{Abstract}

The correlates of variation in the number of males in primate groups form a long-standing question in primatology. We investigated female reproductive seasonality and the numbers of males in groups of wild mandrills (Mandrillus sphinx) in a 25 month camera-trap survey with 160 camera locations in Moukalaba-Doudou National Park, Gabon. We used 1,760 videos to analyse group composition, including the presence of females with new-born infants and with sexual swellings, the number of males present in groups, and male spatial positioning in groups. Female reproduction was seasonal, with a peak in the number of new-borns in the mid-rainy season and a peak in the number of females with sexual swellings in the early dry season. The number of males in the group increased in the dry season, with a much greater increase in the number of mature males (seven-fold) than in sub-mature males (two-fold). The peak number of mature males, but not sub-mature males, in the group lagged significantly behind the peak in the number of females with sexual swellings, suggesting that submature males enter groups before mature males and/or that mature males stay in the group longer after the peak of females with sexual swellings. Mature, but not sub-mature, males appeared frequently near females with sexual swellings. In conclusion, we found a clear relationship between the presence of receptive females and the number of males in the group, and evidence that male competitive ability influences male strategies.

\section{Keywords}

Camera-trap; Mating tactic; Moukalaba-Doudou; Number of males; Video analysis

\section{Introduction}

The determinants of the number of males in a primate group form a long-standing question in primatology (Chapman and Rothman 2009; Kappeler 2000; Kappeler and van Schaik 2002). The 
number of females in a social group correlates tightly with the number of males (Dunbar 2000; Mitani et al. 1996). Seasonal reproduction results in overlapping fertile periods, increasing the number of males in the group (Ridley 1986), within-group synchrony of female cycles is related to an increase in the number of males in a group, while asynchrony is linked to a decrease in the number of males (Carnes et al. 2011; Nunn 1999). Some species experience seasonal changes in the number of males in a group. A field study of red-tailed monkeys (Cercopithecus ascanius) first described a 'male influx', where multiple males enter a social group during the mating season and then mostly depart from the group after the mating season (Struhsaker 1977). Since then, researchers have reported this behaviour in several Old World monkeys, mainly in species with a one-male multi-female social organization (blue monkeys (C. mitis) (Cords et al. 1986; Henzi and Lawes 1987); patas monkeys (Erythrocebus patas) (Harding and Olson 1986; Ohsawa 2003)), but also in multi-male multi-female groups of lesser hill langurs (Semnopithecus entellus hector) (Borries 2000). Females of these species are philopatric and more or less seasonal breeders. In Stuhlmann's blue monkeys (C. m. stuhlmanni), the male influx is largely determined by the number of sexually active females (Cords 2000), which suggests males might decide whether and when to join and leave the group depending on their competitive ability, which varies with their age, rank, and physical features.

Mandrills (Mandrillus sphinx) inhabit tropical forests in central western Africa and form non-nested, extremely large social groups of 300 to over 800 individuals (Abernethy et al. 2002; Hongo 2014). Female mandrills are constantly gregarious and thought to be philopatric (Abernethy and White 2013; Setchell et al. 2008). Studies of a captive colony at the Centre International de Recherches Médicales de Franceville (CIRMF), Gabon, have demonstrated that they have seasonal reproduction with an annual peak of females with exaggerated sexual swellings during the dry season and a birth peak in the mid-rainy season (Setchell et al. 2002; Setchell and Wickings 2004), although female cycles are no more nor less synchronised than expected from a chance distribution (Setchell 
et al. 2011). A wild population at Lopé National Park, Gabon (Abernethy et al. 2002), and a released group at Lékédi Park, Gabon (Brockmeyer et al. 2015), show similar seasonality in the presence of females with sexual swellings, but no study has yet examined birth seasonality in the wild. Most male mandrills become peripheral to the social group after they are about 6 years old, when they begin to develop secondary sexual characteristics (Setchell and Dixson 2002; Setchell et al. 2006). These males are thought to subsequently emigrate from their natal groups to wander independently, as solitary males are often observed in the wild (Abernethy et al. 2002; Hongo 2014). Wild mandrills at Lopé show a seasonal male influx, with numbers of fully-grown, mature males increasing six-fold and numbers of developing sub-mature males increasing two-fold in the dry season (Abernethy et al. 2002). Captive groups at CIRMF also experience an increase in the number of males when females with sexual swellings are available (Setchell 2016).

The mandrill is one of the most sexually dimorphic primates (Leigh et al. 2005; Setchell et al. 2001), and males have a markedly prolonged growth period before attaining adult size (Setchell et al. 2001). Consequently, there are remarkable physical differences and clear dominant/subordinate relationships between mature and sub-mature males (Setchell 2003). Males compete physically with no coalitions, and the rate of injury increases from five years to peak at 11 to 12 years, when they attain full body mass (Setchell et al. 2006). At CIRMF, the dominance rank of males also increases with age: males first win a dominance interaction with a mature male at a mean age of 9.1 years, and some attain the top rank at a mean age of 10.8 years (Setchell et al. 2006). Dominant males aged eight years or more mate-guard females with sexual swellings, following them persistently and preventing other males from gaining access to them (Setchell et al. 2005). Top-ranking males at CIRMF account for $94 \%$ of periovulatory mate-guarding and $69 \%$ of paternity (Setchell et al. 2005). Nevertheless, subordinate males including sub-mature males are proven to mate with females furtively (Setchell et al. 2005). 
to observe the behaviour of wild mandrills directly because of their large home range and poor

100 visibility in dense forest. We collected data indirectly by a large-scale camera-trap survey over more

101 than 2 years and conducted demographic analyses using a large number of video images obtained

102 from the camera-traps. We addressed four aims:

1) To examine female reproductive seasonality, based on the number of females with new-borns and the number of females with sexual swellings. We predicted that a peak of females with newborns would occur during the mid-rainy season, and a peak of females with sexual swellings would occur during the dry season, in accordance with previous studies (Abernethy et al. 2002; Brockmeyer et al. 2015; Setchell et al. 2002; Setchell and Wickings 2004).

2) To examine variation in group composition across the year. We predicted that the numbers of both mature and sub-mature males in the group would increase during the dry season, but that the number of mature males would increase more than that of sub-mature males, in accordance

3) To test the relationship between peaks in the number of females with sexual swellings, mature males, and sub-mature males. We predicted that the peak in the number of mature males would coincide with that of females with sexual swellings, while the peak of the sub-mature males CIRMF (Setchell 2003; Setchell et al. 2006).

4) To analyse the spatial positioning of mature and sub-mature males in groups. We predicted that mature males would stay in proximity to females with sexual swellings at a higher frequency than by chance, but this would be not the case for sub-mature males due to their lower 
competitive ability, based on findings at CIRMF that top-ranking males and dominant mature males are responsible for most mate-guarding behaviour (Setchell et al. 2005).

\section{Methods}

Study Site and Study Population

Our study area encompassed ca. $500 \mathrm{~km}^{2}$ in the eastern part of Moukalaba-Doudou National

Park, Gabon (Fig. 1a). Our base was located at $\mathrm{S} 2^{\circ} 19^{\prime}$ and $\mathrm{E} 10^{\circ} 34^{\prime}$. This area comprises various inundated forest and savannah, and the elevation is 68-723 $\mathrm{m}$ above sea level (Nakashima 2015). The annual rainfall during 2002-2013 fluctuated between 1176 and $2043 \mathrm{~mm}$, and the mean monthly maximum and minimum temperature during 2006-2013 were $26.7-34.3{ }^{\circ} \mathrm{C}$ and $18.7-25.0{ }^{\circ} \mathrm{C}$,

132 respectively (Projet de Conservation de la Biodiversité en Forêt Tropicale à travers la Coexistence

133 Durable entre l'Homme et l'Animal (PROCOBHA), unpublished data). There is one dry season

134 typically from May to September and one rainy season from October to April, and it rains little from

135 December to February in some years (Takenoshita et al. 2008). In our study period, daily rainfall did 136 not exceed $10 \mathrm{~mm}$ from 18 May to 9 October 2012 and from 19 May to 11 October 2013. A previous

137 study in the area obtained three full counts of mandrill groups of 169, 350 and 442 individuals (Hongo 138 2014). 

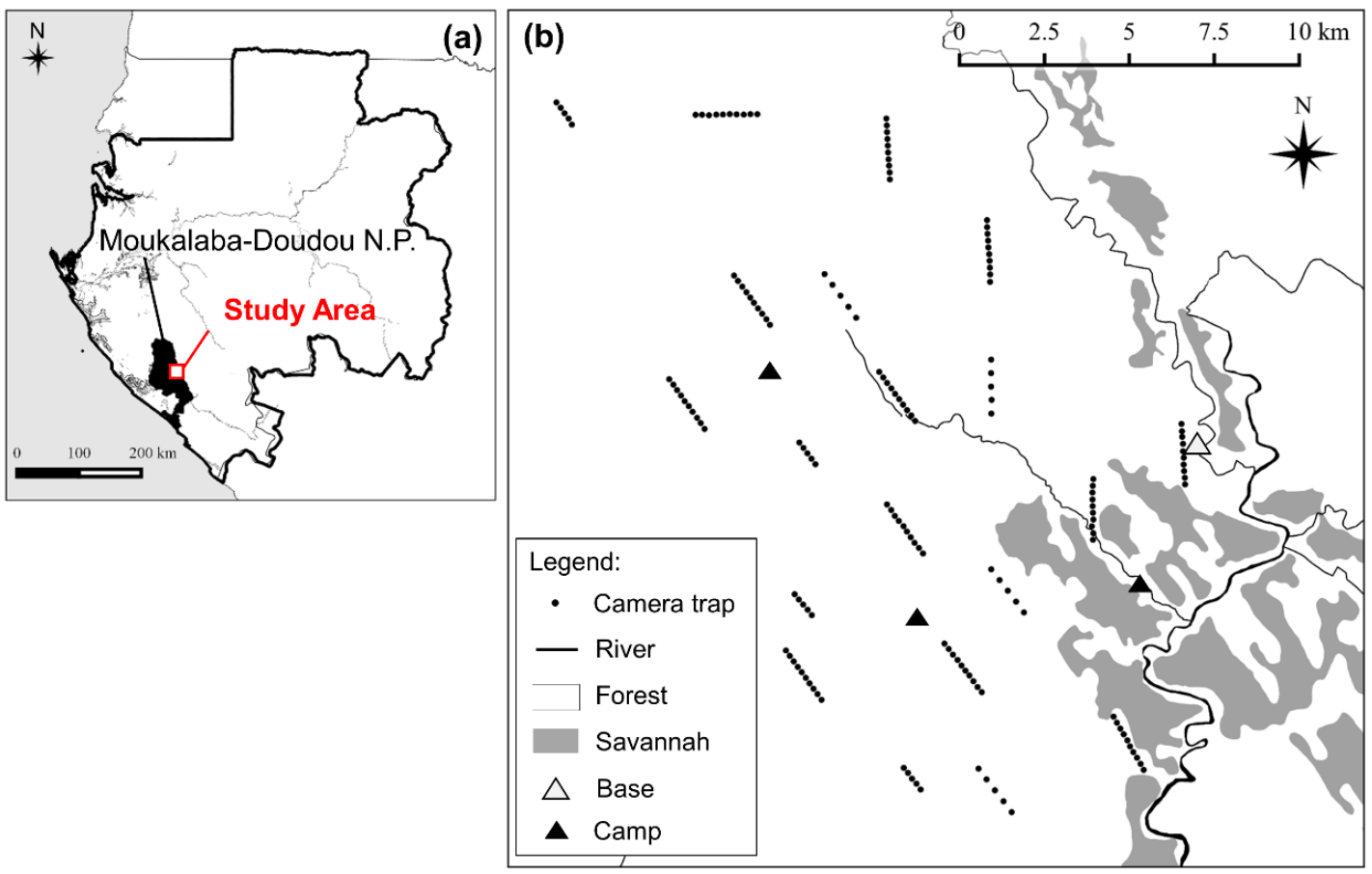

141 Fig. 1 Study area in Moukalaba-Doudou National Park, Gabon (January 2012-February 2014). (a) Locations of Moukalaba-Doudou National Park, Gabon, and the study area. (b) Locations of camera traps in the study area.

\section{Camera Trapping}

We conducted a camera-trap survey for 768 days from 15 January 2012 to 20 February 2014.

Prior to the survey, we established 16 line transects of $2 \mathrm{~km}$ and four of $1 \mathrm{~km}$ in forested areas (Fig. 1b). We deployed five to 10 camera-traps (Bushnell@ Trophy Cam 2010, Kansas, US) along each transect at 200 or $400 \mathrm{~m}$ intervals. We strapped each camera to a tree $10 \mathrm{~m}$ from the line-transect and adjusted it to be parallel to the ground at a height of $30 \mathrm{~cm}$. In total, we deployed cameras at 160 locations. We configured all cameras to start in response to the passage of animals and to record a

152 video image of $30 \mathrm{~s}$ or $60 \mathrm{~s}$ at a minimum interval of $30 \mathrm{~s}$ ( $3 \mathrm{~min}$ from January to July 2012). Longer video recording or shorter interval was impossible because of constraints on the instrument setting 
and battery life. We planted two thin stakes in front of each camera to set the 'counting area', defined as 'within $5 \mathrm{~m}$ of the cameras'. We visited all transects monthly to monitor the cameras and change batteries if needed.

\section{Video Analysis}

We used only images containing mandrills for the current study. We defined a 'visit' as consecutive video images taken by the same camera at an interval of less than $30 \mathrm{~min}$ (O'Brien et al. 2003). That is, we regarded two videos filmed at a $\geq 30 \mathrm{~min}$ interval or taken by different cameras as two independent visits.

Based on information from previous studies of captive mandrills (Dixson 2015; Setchell and Dixson 2002; Setchell et al. 2001, 2002) as well as our own observations at CIRMF and Kyoto City Zoo, we classified recorded animals into age-sex classes as follows:

- New-borns (0-2 months old): infants with white pelage, clinging to their mothers ventro-ventrally. - Larger infants and juveniles (3 months to 3 years old): infants and juveniles distinguishable from new-borns by their olive pelage.

- Reproductive females (4 years or older): reproductively mature females that we further classified into three categories: females with new-borns, females with (follicular-phase) sexual swellings, and females without a new-born and with no (follicular-phase) sexual swelling. We categorised females with pregnancy swellings, which are clearly distinguishable from follicular-phase swellings (Dixson 2015; Setchell and Wickings 2004), as females without a new-born and with no sexual swelling.

- Pubescent males (4-5 years old): males whose body lengths are similar to those of reproductive females (ca. 50-60 cm) and with small testes.

- 'Indistinguishable individuals A': animals that we could not distinguish among pubescent males, 
females with sexual swellings, and females without a new-born and with no sexual swelling, because we could not observe their genitals.

- 'Indistinguishable individuals B': pubescent males or females without a new-born and with no

181 sexual swelling.

182

- Sub-mature males (6-9 years old): males whose body lengths are larger than those of reproductive females (ca. $60-70 \mathrm{~cm}$ ), whose testes are larger than those of pubescent males, and whose secondary sexual adornments have begun to develop.

- Mature males (10 years or older): fully grown males that have attained a body length estimated to be $70 \mathrm{~cm}$ or more.

- Unknowns: animals that we could not classify.

Since we do not know whether the physical characters of wild mandrills develop at the same rate as those of captive animals, and we did not know the ages of the animals, the ages attributed here are approximate guides. Studies at CIRMF (Setchell 2016) use 'adolescent males' for sub-mature males, and 'adult males' for mature males. We followed Abernethy et al. (2002)'s terms because we estimated ages of animals based on video images of unknown animals, and because we categorized pubescent males as a different class from sub-mature males, both of which are termed adolescent males at CIRMF (Setchell 2003).

We defined a 'group visit' as a visit that contained two or more individuals and included at least one reproductive female, juvenile, or infant. We used only group visits in analysis. We used only individuals who passed within the counting area for statistical analyses.

We recorded sexual interactions (i.e., copulations and genital inspections) and inter-male aggression (i.e., head-bobs, lunges, supplanting, and physical attacks) observed during group visits. We also noted mate-guarding, defined as 'remaining or walking within $3 \mathrm{~m}$ of a female with a sexual swelling'. We also categorized the positional relationships of the mate-guarding pairs as 'a male 
precedes a female with a sexual swelling', 'a male follows a female with a sexual swelling', or 'position unclear'.

\section{Statistical Analysis}

We examined seasonality in group composition and male positioning by constructing generalized linear mixed models (GLMMs) with a binomial error distribution and a logit link function, followed by model selection using Akaike's Information Criteria (AIC) (Akaike 1974; Burnham and Anderson 2002). We constructed GLMMs using the function 'glmmML' in the R-package glmmML (Bronstrom 2013). In each model selection procedure, we selected the model with the smallest AIC value as the 'best model' among biologically meaningful candidate model sets, and used models whose AIC differed from the best model ( $\triangle \mathrm{AIC}$ ) by less than 2.0 for multi-model inference (Burnham and Anderson 2004). In all statistical tests, we considered $\mathrm{P}<0.05$ as significant. We performed all analyses using $\mathrm{R}$ version 3.2.2 (R Core Team 2015).

\section{Reproductive seasonality}

We tested the seasonality of the presence of new-borns and of females with sexual swellings using GLMM polynomial regressions. We created data sets by counting the individuals in a group visit. Variables in the full model for the new-born seasonality were as follows: dependent variable $=$ number of females with new-borns/number of all reproductive females; fixed effect $=6$ th-order polynomial of day of the year (continuous variable of $1-365,1=1$ st January); random effect $=$ individual visit (random intercept). Similarly, variables in the full model for the seasonality of female sexual swellings were as follows: dependent variable $=$ number of females with sexual swellings/number of all reproductive females; fixed effect $=6$ th-order polynomial of day of the year; random effect $=$ individual visit. 
Variation in the number of males in the group

We tested for variation in the number of mature and sub-mature males in the group across

the year using GLMM polynomial regressions. Variables in the full model for the number of mature

males in the group were as follows: dependent variable $=$ number of mature males/number of $\geq 4$ -

year-old individuals except sub-mature males (i.e., mature males, pubescent males, and reproductive

females); fixed effect $=6$ th-order polynomial of day of the year; random effect $=$ individual visit.

Variables in the full model for the number of sub-mature males in the group were as follows:

dependent variable $=$ number of sub-mature males/number of $\geq 4$-year-old individuals except mature

males (i.e., sub-mature males, pubescent males, and reproductive females); fixed effect $=6$ th-order

infants or juveniles in the denominators of the dependent variables above because births may be seasonal and including these classes may make it difficult to obtain a precise estimate of male number.

in each 2-month period (January-February, March-April, etc.) was significantly different from 1.0.

$245\left(\mathrm{SF}^{\mathrm{crt}}\right)$ in a given month as:

$$
\mathrm{SF}^{\mathrm{crt}}=\mathrm{SF}+\mathrm{InA} \times \frac{\mathrm{SF}}{\mathrm{PM}+\mathrm{SF}+\mathrm{NF}}
$$


'Indistinguishable individuals A', PM is the number of pubescent males, and NF is the number of females without a new-born and with no sexual swelling. Similarly, we calculated the corrected number of females without a new-born and with no sexual swelling $\left(\mathrm{NF}^{\mathrm{crt}}\right)$ in a given month as:

$$
\mathrm{NF}^{\mathrm{crt}}=\mathrm{NF}+\operatorname{InA} \times \frac{\mathrm{NF}}{\mathrm{PM}+\mathrm{SF}+\mathrm{NF}}+\operatorname{InB} \times \frac{\mathrm{NF}}{\mathrm{PM}+\mathrm{NF}}
$$

where NF is the original number of females without a new-born and with no sexual swelling, InB is the number of 'Indistinguishable individuals B', and the other abbreviations refer to the same classes as in the formula (1). Subsequently, we summed the corrected number of females with sexual swellings and the number of mature males in each 2-month period, and compared them using a twotailed binomial test. As we conducted this test for the six periods separately, we adjusted P values using Holm's method (Holm 1979).

\section{Relationships between the timing of peak numbers of females with sexual swellings, mature males} and sub-mature males

We tested whether the days when numbers of females with sexual swellings, mature males, and sub-mature males reached a peak were different from each other using a bootstrap method using the difference between two peaks (in days) as a test statistic. We created each bootstrap sample from the original data set and calculated the day of each peak using the best model, then calculated the day difference between the two peaks, obtaining a bootstrapped test statistic value. We repeated this bootstrap resampling procedure 10,000 times to construct a probability distribution of this value, and calculated the probability that the bootstrapped value was equal or larger than the observed one, using this as the P value. As we conducted this test for three pairs (females with sexual swellings vs. mature males, females with sexual swellings vs. sub-mature males, and mature males vs. sub-mature males), 
we adjusted the P values using Holm's method (Holm 1979).

\section{Male spatial positioning and mate-guarding}

Prior to the analyses described in this section, we adjusted the time length of all the videos to $30 \mathrm{~s}$ by discarding the second half of $60 \mathrm{~s}$ videos, to give each video equal weight in our analysis.

To test whether males appeared at higher rates in videos including at least one female with a sexual swelling than those without a female with a sexual swelling, we constructed two GLMMs. We created data sets by counting individuals by video image, not by visit. Variables in the full model for the mature male-positioning were as follows: dependent variable $=$ number of mature males/number of all individuals except new-borns and infants clinging to their mothers; fixed effects $=$ presence/absence of a female with a sexual swelling (categorical variable), 3rd-order polynomial of day of the year, and interactions between the above two effects; random effect = individual visits (random intercept). Likewise, variables in a full model for the sub-mature male-positioning were as follows: dependent variable $=$ number of sub-mature males/number of all individuals except newborns and infants clinging to their mothers; fixed effects = presence/absence of a female with a sexual swelling (categorical variable), 3rd-order polynomial of day of the year, and interactions between the two effects; random effect $=$ individual visits. We did not include the 4 th or more order of day as a fixed effect in the full models for male positioning because the calculations failed to converge when we did so.

In addition, we extracted videos including at least one female with a sexual swelling and one mature male and/or sub-mature male, and tested whether the proportion of mature males and submature males showing mate-guarding differed using a two-tailed Fisher's exact test.

Ethical Note 
299 Primatological Society and the laws of the Gabonese Republic and was conducted with approval from

300 the Centre National de la Recherche Scientifique et Technologique (permission number AR0031/11)

301 and the Agence Nationale des Parcs Nationaux (permission numbers 000017, 000022).

302

303 Results

304

The survey period included 64,854 camera-days (daily mean functioning camera $=84.4 \pm$

305 SD 22.8, range: 7-128). We identified 303 mandrill group visits (i.e., $0.47 \%$ of camera-days)

306 containing a total of 1,760 video images and counted 5,906 individuals. A group visit contained a mean of $5.5 \pm$ SD 6.1 video images and a mean of $19.5 \pm$ SD 24.8 mandrills in the counting area. We successfully classified $97.9 \%$ of individuals into an age-sex class (Table 1). 
309 Table 1 Monthly counts of mandrills (Mandrillus sphinx) by age-sex class, based on a camera trap survey in Moukalaba-Doudou National Park, Gabon

310 (January 2012-February 2014).

\begin{tabular}{|c|c|c|c|c|c|c|c|c|c|c|c|c|}
\hline \multirow[t]{3}{*}{ Month } & \multicolumn{11}{|c|}{ Number of individuals ( $\%$ of the total number of individuals) } & \multirow{3}{*}{$\begin{array}{l}\text { Secondary } \\
\text { sex ratio }^{b}\end{array}$} \\
\hline & \multirow{2}{*}{$\begin{array}{l}\text { New- } \\
\text { borns }\end{array}$} & \multirow{2}{*}{$\begin{array}{l}\text { Larger } \\
\text { infant and } \\
\text { juveniles }\end{array}$} & \multicolumn{3}{|c|}{ Reproductive females [\% of total females] } & \multirow{2}{*}{$\begin{array}{l}\text { Total } \\
\text { reproductive } \\
\text { females }\end{array}$} & \multirow{2}{*}{$\begin{array}{l}\text { Pubescent } \\
\text { males }^{\text {a }}\end{array}$} & \multirow{2}{*}{$\begin{array}{l}\text { Sub-mature } \\
\text { males }\end{array}$} & \multirow{2}{*}{$\begin{array}{l}\text { Mature } \\
\text { males }\end{array}$} & \multirow[t]{2}{*}{ Unknown } & \multirow[t]{2}{*}{ Total } & \\
\hline & & & $\begin{array}{l}\text { Females with } \\
\text { a new-born }\end{array}$ & $\begin{array}{l}\text { Females with } \\
\text { a sexual } \\
\text { swelling }^{\text {a }}\end{array}$ & $\begin{array}{l}\text { Females without a } \\
\text { new-born and with } \\
\text { no sexual swelling }\end{array}$ & & & & & & & \\
\hline Jan. & $89(10.4)$ & $310(36.3)$ & 89 [32.0] & $3.6[1.3]$ & $185.2[66.7]$ & $277.9(32.6)$ & $105.1(12.3)$ & $49(5.7)$ & $8(0.9)$ & $14(1.6)$ & 853 & 4.9 \\
\hline Feb. & $41(6.1)$ & $275(40.9)$ & $41[22.1]$ & $5.8[3.1]$ & $138.5[74.8]$ & $185.3(27.6)$ & $91.7(13.6)$ & $59(8.8)$ & $6(0.9)$ & $14(2.1)$ & 672 & 2.9 \\
\hline Mar. & $1(0.5)$ & $75(39.7)$ & $1[1.8]$ & $4.0[7.0]$ & $51.2[91.2]$ & $56.2(29.7)$ & $31.8(16.8)$ & $18(9.5)$ & $4(2.1)$ & $3(1.6)$ & 189 & 2.6 \\
\hline Apr. & $4(2.3)$ & $80(45.2)$ & $4[6.8]$ & $7.7[13.1]$ & $47.0[80.1]$ & $58.7(33.2)$ & $14.3(8.1)$ & $11(6.2)$ & $5(2.8)$ & $4(2.3)$ & 177 & 3.7 \\
\hline May & $1(0.2)$ & $184(44.9)$ & $1[0.8]$ & 36.4 [29.7] & 85.0 [69.5] & $122.3(29.8)$ & $25.7(6.3)$ & $46(11.2)$ & $18(4.4)$ & $13(3.2)$ & 410 & 1.9 \\
\hline Jun. & $1(0.4)$ & $82(29.9)$ & $1[0.8]$ & 24.3 [20.6] & 92.7 [78.5] & $118.0(43.1)$ & $19.0(6.9)$ & $33(12.0)$ & $14(5.1)$ & $7(2.6)$ & 274 & 2.5 \\
\hline Jul. & $0(0.0)$ & $135(36.0)$ & $0[0.0]$ & $17.5[13.2]$ & $115.4[86.8]$ & $132.9(35.5)$ & $36.1(9.6)$ & $42(11.2)$ & $19(5.1)$ & $10(2.7)$ & 375 & 2.2 \\
\hline Aug. & $3(0.8)$ & 147 (37.9) & $3[2.1]$ & $14.9[10.4]$ & $125.3[87.5]$ & $143.2(36.9)$ & $25.8(6.6)$ & $44(11.3)$ & $20(5.2)$ & $5(1.3)$ & 388 & 2.2 \\
\hline Sep. & $0(0.0)$ & 204 (37.4) & $0[0.0]$ & $28.4[14.4]$ & $169.0[85.6]$ & $197.4(36.2)$ & $48.6(8.9)$ & $60(11.0)$ & $22(4.0)$ & $13(2.4)$ & 545 & 2.4 \\
\hline Oct. & $11(1.2)$ & $390(44.3)$ & $11[4.4]$ & $12.4[5.0]$ & $225.3[90.6]$ & $248.7(28.2)$ & $98.3(11.2)$ & $67(7.6)$ & $46(5.2)$ & $20(2.3)$ & 881 & 2.2 \\
\hline Nov. & $18(2.9)$ & $319(50.7)$ & 18 [11.4] & $8.2[5.2]$ & $132.2[83.5]$ & $158.4(25.2)$ & $60.6(9.6)$ & $47(7.5)$ & $13(2.1)$ & $13(2.1)$ & 629 & 2.6 \\
\hline Dec. & 39 (7.6) & $232(45.2)$ & 39 [27.5] & $7.1[5.0]$ & 95.9 [67.5] & $142.1(27.7)$ & $59.9(11.7)$ & $22(4.3)$ & $9(1.8)$ & $9(1.8)$ & 513 & 4.6 \\
\hline Total & $208(3.5)$ & $2433(41.2)$ & 208 [11.3] & $178.6[9.7]$ & $1460.6[79.1]$ & $1847.2(31.3)$ & $610.8(10.3)$ & $498(8.4)$ & $184(3.1)$ & $125(2.1)$ & 5906 & - \\
\hline
\end{tabular}

$311{ }^{\mathrm{a}}$ Numbers are corrected for indistinguishable individuals (see Methods); ${ }^{\mathrm{b}}$ Ratio of the number of reproductive females to the number of mature and sub-

312 mature males 


\section{Reproductive Seasonality}

The proportion of females with new-borns among all reproductive females varied across the year, with an annual peak in the mid-rainy season, although we observed at least one female with a new-born in all months except July and September (Table 1). Correcting the numbers of females with sexual swellings and females without a new-born and with no sexual swelling for animals that we could not distinguish (see Methods), females with new-borns accounted for $32.0 \%$ of reproductive females in January and $27.5 \%$ in December. We counted only 10 females with new-borns in total from March to September (1.2\% of reproductive females during this period). The best polynomial regression model contained the 2nd-order polynomial of day as a fixed effect, and the second best model showed a similar regression curve to the best model (Fig. 2a; Table 2).

The proportion of females with sexual swellings among all reproductive females showed a peak in the early dry season, although we observed at least one female with a sexual swelling in all months (Table 1). After correcting for animals that we could not distinguish, females with sexual swellings accounted for $29.7 \%$ of reproductive females in May and $20.6 \%$ in June, while they accounted for only $3.7 \%$ of reproductive females from October to February. The best model contained the 3rd-order polynomial of day as a fixed effect, indicating that the proportion of females with sexual swellings decreased more gradually than it increased (Fig. 2b; Table 2). The second best model showed a regression curve similar to that of the best model. According to the best model, the peak in the proportion of females with sexual swellings occurred on the 156th day of the year (5 June). 


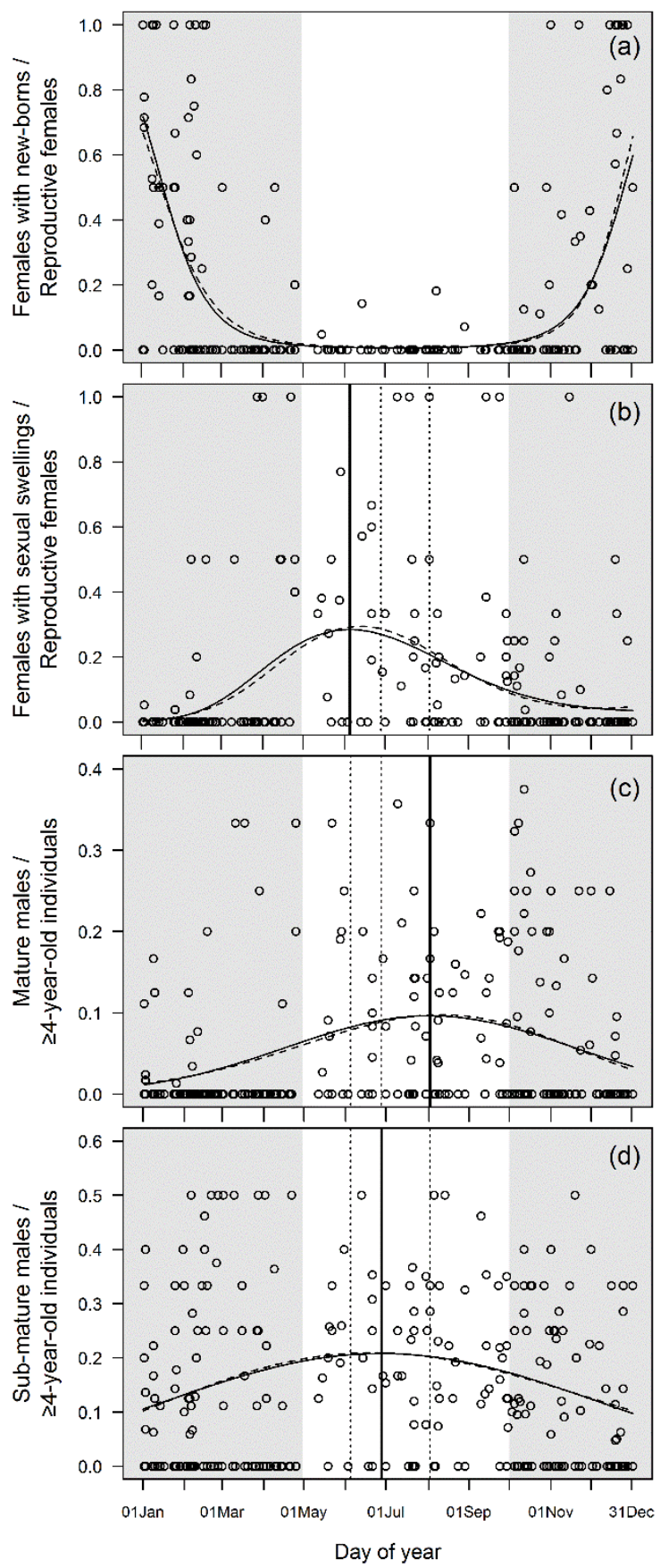

333 Fig. 2 Variation in the proportions of (a) females with new-borns, (b) females with sexual swellings,

334 (c) mature males, and (d) sub-mature males mandrills in social groups at Moukalaba-Doudou National

335 Park, Gabon (January 2012-February 2014). Data points represent individual group visits. Regression

336 curves of the best (solid) and the second best model (dashed) are shown. Vertical lines represent peak

337 days of females with sexual swellings, sub-mature males, and mature males from left to right. Typical dry season (white area) and rainy season (shaded area) are indicated 
339 Table 2 Parameter estimates, AIC, and $\Delta$ AIC values for models of female reproductive seasonality and numbers of mature and sub-mature male mandrills in

340 social groups at Moukalaba-Doudou National Park, Gabon (January 2012-February 2014). Models with $\Delta$ AIC $<2.0$ are shown.

\begin{tabular}{|c|c|c|c|c|c|c|c|}
\hline \multirow[t]{2}{*}{ Order } & \multirow[t]{2}{*}{$\operatorname{AIC}(\triangle \mathrm{AIC})$} & \multicolumn{6}{|c|}{ Parameter estimate / SE } \\
\hline & & Intercept & Day & Day $^{\wedge} 2$ & Day`3 $^{\wedge}$ & Day$^{\wedge} 4$ & Random effect \\
\hline \multicolumn{8}{|c|}{ Number of females with new-borns among all reproductive females $(\mathrm{N}=238)$} \\
\hline 1 & $257.9(0.0)$ & $1.1 / 0.33$ & $-0.065 /-0.0071$ & $1.7 \times 10^{-4} / 1.9 \times 10^{-5}$ & - & - & $1.2 / 0.23$ \\
\hline 2 & $259.0(1.1)$ & $0.80 / 0.43$ & $-0.053 / 0.015$ & $8.8 \times 10^{-5} / 9.2 \times 10^{-5}$ & $1.5 \times 10^{-7} / 1.6 \times 10^{-7}$ & - & $1.2 / 0.23$ \\
\hline
\end{tabular}

Number of females with sexual swellings among all reproductive females $(\mathrm{N}=238)$

$1 \quad 218.1(0.0) \quad-6.0 / 0.80 \quad 0.076 / 0.016 \quad-3.5 \times 10^{-4} / 9.3 \times 10^{-5}$

$2 \quad 219.4(1.3) \quad-5.4 / 1.0 \quad 0.050 / 0.034 \quad-6.5 \times 10^{-5} / 3.4 \times 10^{-4} \quad-6.8 \times 10^{-7} / 1.3 \times 10^{-6} \quad 1.5 \times 10^{-9} / 1.7 \times 10^{-9} \quad 0.64 / 0.19$

Number of mature males among $\geq 4$-year-old individuals except sub-mature males $(\mathrm{N}=286)$

$\begin{array}{llllllll}1 & 282.2(0.0) & -4.5 / 0.35 & 0.021 / 0.0040 & -4.9 \times 10^{-5} / 1.0 \times 10^{-5} & - & - & 0.64 / 0.13 \\ 2 & 284.0(1.8) & -4.3 / 0.45) & 0.016 / 0.010 & -2.0 \times 10^{-5} / 6.5 \times 10^{-5} & -5.2 \times 10^{-8} / 1.1 \times 10^{-7} & - & 0.64 / 0.13\end{array}$

Number of mature males among $\geq 4$-year-old individuals except mature males $(\mathrm{N}=290)$

\begin{tabular}{llllllll}
1 & $385.7(0.0)$ & $-2.1 / 0.16$ & $0.0091 / 0.0022$ & $-2.5 \times 10^{-5} / 6.1 \times 10^{-6}$ & - & - & $0.39 / 0.090$ \\
2 & $387.6(1.9)$ & $-2.2 / 0.21$ & $0.011 / 0.0057$ & $-3.6 \times 10^{-5} / 3.7 \times 10^{-5}$ & $1.9 \times 10^{-8} / 6.6 \times 10^{-8}$ & - & $0.39 / 0.090$ \\
\hline
\end{tabular}



individuals on 10 January), and increased to $8.3 \%$ on the day when the number of females with sexual swellings peaked. Thereafter, the proportion continued to increase gradually to a peak on the 215 th these results, a group size of 350 including 160 pubescent males and reproductive females (as recorded at Moukalaba-Doudou, Hongo 2014) should include 2-3 mature males in January, with the number increasing to 14-15 around the day of peak numbers of females with sexual swellings and about 17 around the day of peak numbers of mature males. season (Fig. 2d). The best model contained the 2nd-order polynomial of day as a fixed effect, and the regression curve of the second best model showed a similar pattern (Table 2). According to the best model, the proportion of sub-mature males was lowest in December (e.g., $10.8 \%$ of $\geq 4$-year-old

361 individuals on 20 December), increased two-fold to a peak on the 179th day (28 June, 20.8\%), then started to decline. Based on these results, a group of 350 including 160 pubescent males and increasing to about 42 on the day of peak numbers of sub-mature males. 
significantly larger than 1.0 only in May-June (Table 3), the period of the peak in the numbers of females with sexual swellings and sub-mature males. The ratios in the other 2-month periods were not statistically different from 1.0 (Table 3 ).

Table 3 Numbers of females with sexual swellings and mature males in mandrill social groups, based on a camera trap survey in Moukalaba-Doudou National Park, Gabon (January 2012-February 2014), and $\mathrm{P}$ values from binomial test with Holm's adjustment.

\begin{tabular}{llll}
\hline 2-month period & $\begin{array}{l}\text { Number of females } \\
\text { with sexual swellings }\end{array}$ & Number of mature males & P value \\
\hline January-February & 9 & 14 & $0.40^{\text {a }}$ \\
March-April & 12 & 9 & $0.66^{\text {a }}$ \\
May-June & 61 & 32 & 0.02 \\
July-August & 32 & 39 & $0.48^{\text {a }}$ \\
September-October & 41 & 68 & 0.062 \\
November-December & 15 & 22 & $0.32^{\text {a }}$ \\
\hline
\end{tabular}

${ }^{\mathrm{a}} \mathrm{P}$ values are not adjusted because they are larger than 0.05

Relationships between the Timing of Peak Numbers of Females with Sexual Swellings, Mature Males and Sub-mature Males

The peak in the number of mature males lagged significantly behind both the peak in the number of females with sexual swellings (bootstrap test with Holm's adjustment: $\mathrm{N}=10,000$, observed time lag $=59$ days, $\mathrm{P}=0.013)$ and the peak in the number of sub-mature males $(\mathrm{N}=10,000$, lag $=36$ days, $\mathrm{P}=0.026$ ). The lag in the peak in the number of sub-mature males to the peak in the number of females with sexual swelling was not statistically significant $(\mathrm{N}=10,000, \operatorname{lag}=23$ days, 
$\mathrm{P}=0.13)$

\section{Male Spatial Positioning and Mate-guarding}

Overall, $21.0 \%$ (37/176) of mature males occurred in videos containing at least one female with a sexual swelling. The best model included the 2 nd-order polynomial of day and the presence of females with sexual swellings (Table 4), indicating that the presence of females with sexual swellings positively affected the proportion of mature males, even after the seasonal effect was considered (Fig. 3). In addition, the best model (but not the second best model) also included the interaction term (Table 4), indicating that the proportion of mature males was continuously high in the vicinity of females with sexual swellings even during the birth season although the proportion of mature males in videos without a female with a sexual swelling fluctuated seasonally (Fig. 3). In contrast, the presence of females with sexual swellings had no effect on the proportion of sub-mature males. Only $10.9 \%$ (49/451) of sub-mature males occurred in videos containing females with sexual swellings, and the best model contained only the 2nd-order polynomial of day as a fixed effect (Table 4). Although the third best model included the presence of females with sexual swellings, the estimated parameter was negative.

Among males recorded with one or more females with sexual swellings in the same video, more than half of mature males $(19 / 37,51.4 \%)$ showed mate-guarding, whereas a significantly lower proportion of sub-mature males $(7 / 49,14.3 \%)$ did so (Fisher's exact test: odds ratio $=6.18, \mathrm{P}<0.001)$.

Of the 19 mature males mate-guarding, 11 followed females with sexual swellings, none preceded females with sexual swellings, and 8 of the relative positions were unclear. We also observed copulation by mature males three times and by sub-mature males twice, and genital inspection of females with sexual swellings once by a mature male and twice by sub-mature males. We observed inter-male aggression six times, three of which were between a mature male and a sub-mature male. 
407

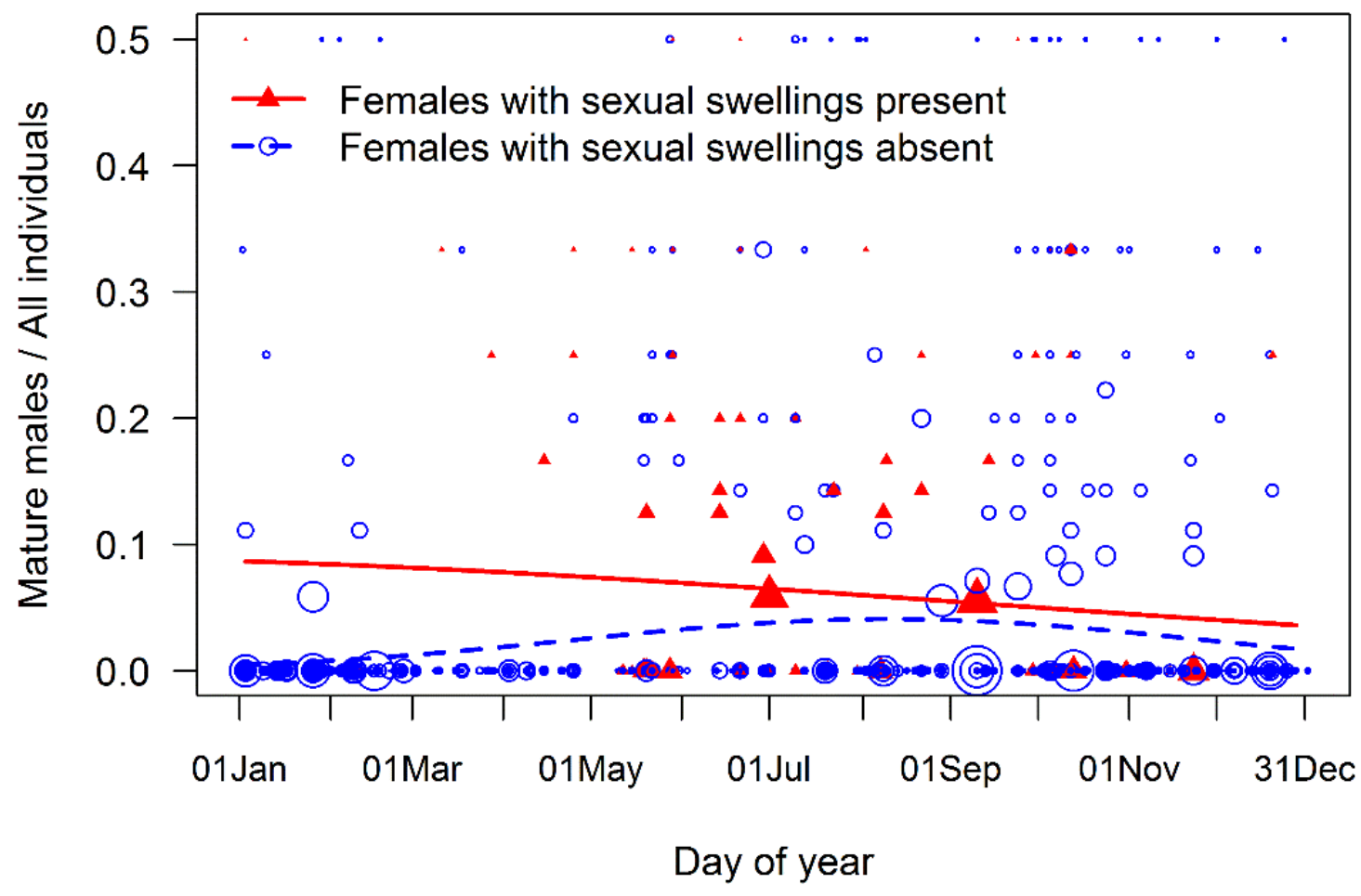

408

409 Fig. 3 Effect of the presence of a female with a sexual swelling and day of year on the spatial

410 positioning of mature male mandrills in social groups at Moukalaba-Doudou National Park, Gabon

411 (January 2012-February 2014). Data points show individual video images, and the size of data points

412 is proportional to number of individuals counted, which reflects the relative importance in regression.

413 Lines show regression curves of the best model 
414 Table 4 Parameter estimates, AIC, and $\triangle \mathrm{AIC}$ values for models of spatial positioning in mature males and sub-mature male mandrills in social groups at

415 Moukalaba-Doudou National Park, Gabon (January 2012-February 2014). Models with $\Delta$ AIC $<2.0$ are shown.

\begin{tabular}{|c|c|c|c|c|c|c|c|c|c|}
\hline \multirow[t]{2}{*}{ Order } & \multirow[t]{2}{*}{$\operatorname{AIC}(\triangle \mathrm{AIC})$} & \multicolumn{8}{|c|}{ Parameter estimate / SE } \\
\hline & & Intercept & Day & $\operatorname{Day}^{\wedge} 2$ & $\mathrm{Day}^{\wedge} 3$ & $\begin{array}{l}\text { Females with } \\
\text { sexual } \\
\text { swellings } \\
\text { present }\end{array}$ & $\begin{array}{l}\text { Day : Females } \\
\text { with sexual } \\
\text { swellings } \\
\text { present }^{\text {a }}\end{array}$ & $\begin{array}{l}\text { Day^2: Females } \\
\text { with sexual } \\
\text { swellings present }{ }^{a}\end{array}$ & Random effect \\
\hline \multicolumn{10}{|c|}{ Number of mature males among all individuals except new-borns and infants clinging to their mothers $(\mathrm{N}=1,627)$} \\
\hline 1 & $761.9(0.0)$ & $-5.4 / 0.38$ & $0.020 / 0.0044$ & $-4.6 \times 10^{-5} / 1.1 \times 10^{-5}$ & - & $3.1 / 1.0$ & $-0.021 / 0.011$ & $4.1 \times 10^{-5} / 2.8 \times 10^{-5}$ & $0.67 / 0.14$ \\
\hline \multicolumn{10}{|c|}{ Number of sub-mature males among all individuals except new-borns and infants clinging to their mothers $(\mathrm{N}=1,627)$} \\
\hline 1 & $1409.2(0.0)$ & $-2.8 / 0.17$ & $0.0081 / 0.0023$ & $-2.4 \times 10^{-5} / 6.3 \times 10^{-6}$ & - & - & - & - & $0.45 / 0.093$ \\
\hline 2 & $1410.5(1.3)$ & $-2.9 / 0.22$ & $0.013 / 0.0058$ & $-5.7 \times 10^{-5} / 3.8 \times 10^{-5}$ & $6.0 \times 10^{-8} / 6.9 \times 10^{-8}$ & - & - & - & $0.45 / 0.093$ \\
\hline
\end{tabular}

$416{ }^{\mathrm{a}}$ Interaction terms 


\section{Discussion}

In this study, demographic analyses of video images obtained using camera-traps revealed seasonal patterns of the presence of new-borns and sexual swellings in a wild mandrill population. Our results also showed influxes of both mature and sub-mature males when many females showed sexual swellings and that the numbers of mature males in the group varied more than the number of sub-mature males. Mature and sub-mature males also differed in the timing of the peak numbers and in spatial positioning relative to females with sexual swellings.

\section{Reproductive Seasonality}

Our analyses of female reproduction showed seasonality, with a peak in the presence of new-borns in the mid-rainy season and a peak in sexual swellings in the early dry season, generally as predicted (Fig. 2a, b). We observed most new-borns between November and February (Table 1), in accordance with breeding seasonality in captive groups at CIRMF (Setchell et al. 2002). This is the period when fruits are most abundant in the study area (Takenoshita et al. 2008). Since mandrills prefer ripe fruits (Hoshino 1985; Rogers et al. 1996), this may be a female reproductive strategy to give birth and begin lactation during the best period for nutritional intake, in common with many other tropical and sub-tropical primates in Africa and South America (Butynski 1988; Di Bitetti and Janson 2000; Janson and Verdolin 2005; Nakagawa 2000). The proportion of females with new-borns in January (32.0\% of reproductive females, Table 1), suggests that females in the study population may give birth on average once every three years. This estimated interbirth interval is much longer than that observed at CIRMF (405 days, Setchell et al. 2002), and similar to that assumed at Lopé (around two years, Abernethy and White 2013).

Most females showing sexual swellings appeared between April and September (Table 1), as found for captive groups at CIRMF (Setchell and Wickings 2004) and a wild population at Lopé 
441 (Abernethy et al. 2002). Birth seasonality was more distinct than seasonality of sexual swellings,

442 suggesting that the seasonal pattern of conceptive cycles is tighter than that of sexual swellings

443 (female mandrills may take several swelling cycles to conceive, Setchell and Wickings 2004).

444 Nevertheless, we observed both females with sexual swellings and females with new-borns in almost

445 all months (Table 1), as reported at CIRMF (Setchell et al. 2002; Setchell and Wickings 2004). This

446 suggests that reproduction is not confined to particular months. Females may cycle outside the usual 447 mating season if they lose their infant (Setchell et al. 2002) and are in appropriate physical condition 448 to conceive and nurse an infant. Moreover, the proportion of females with sexual swellings decreased 449 more slowly than it increased (Fig. 2b), probably due to multiple cycles in females (Setchell and 450 Wickings 2004).

Variation in the Number of Males in the Group although the increase was much greater in mature males (seven-fold) than in sub-mature males (twofold) (Fig. 2c, d), in line with findings for mandrills at Lopé (Abernethy et al. 2002). This age difference may be at least partially due to the year-round group membership of younger, natal submature males which have not yet dispersed (Setchell et al. 2006). In addition, the two age classes may differ in ranging behaviour when they are not in the group. In Japanese macaques (Macaca fuscata), younger non-group males sometimes associate with group members during the non-mating season,

460 while fully-grown non-group males tend to remain solitary during this period (Kawazoe 2015).

461 Solitary sub-mature, but not mature, male mandrills may also sometimes visit groups outside the mating season, resulting in the observation of sub-mature males in groups in other months. 
and sub-mature males, since the ratio of pubescent males to reproductive females, which stay in groups year-round and whose numbers should be stable, was apparently lower during the mating season (0.16-0.27 in April to September, Table 1) than during the birth season $(0.38-0.49$ in November to February, Table 1). Increasing conflicts with older males in the mating season may precipitate emigration of pubescent males from their natal groups (Dixson 2015). However, our results for pubescent males must be regarded as preliminary, because we could not always distinguish between pubescent males and reproductive females, and our camera-traps rarely filmed solitary pubescent males during the study period. At Lopé, males estimated to be aged five years or younger were not found alone and the number of such males in groups did not vary seasonally (Abernethy et al. 2002). We need further detailed investigations before offering any conclusion on this topic.

Relationships between the Timing of Peak Numbers of Females with Sexual Swellings, Mature Males and Sub-mature Males

Contrary to our prediction, the peak in the number of mature males lagged behind that of females with sexual swellings by about two months (Fig. 2). These results may be due to a bias derived from partial records of very large groups by camera-trapping, as age-sex classes show positional differences when mandrill groups cross open areas (Hongo 2014). It is, however, unlikely that these positional differences occurred in the groups filmed in our study for two reasons. First, we installed all camera-traps in forested areas where the animals are less cautious than in open areas. The positional patterns in the group progression are very weak when the animals are less cautious (Hongo 2014) and only juveniles reacted to our camera-traps. Second, our video images included foraging and resting groups, in which the progression patterns should be unclear, as well as moving groups. We therefore suggest that our findings do not result from methodological bias. 
the differences in their joining or leaving the group, or both. We therefore discuss each of the two potential factors separately. In terms of joining, some, but not all, mature males may have entered groups sometime after the peak in the number of females with sexual swellings, while sub-mature males tended to join groups ahead of the increase in the number of mature males (Fig. 2c, d). This may be due to differences in ranging behaviour when the males are outside groups, as discussed above. Solitary males generally travel shorter distances or for less time than do group males (yellow baboons (Papio cynocephalus) Slatkin and Hausfater 1976; mountain gorillas (Gorilla beringei beringei) Yamagiwa 1986); therefore, if solitary mandrills range entirely independently during the non-mating season, it may be difficult to find groups and to monitor the reproductive status of females regularly, because groups are highly nomadic (White et al. 2010) and group density is crucially low (White 1994). Non-resident sub-mature males may range not so far from groups and regularly visit groups so as not to miss the peak in the number of females with sexual swellings. The number of females with sexual swellings significantly exceeded that of mature males only in May-June, the period around the peak in numbers of such females (Table 3). This suggests that mature males may be not able to exclude sub-mature males from all mating opportunities at this time, and therefore it may be the most attractive period for sub-mature males to mate with non-guarded females. In contrast, nonresident mature males may be more independent because the energy costs of ranging around groups should be very high due to their exceedingly large body size, and so they may not always find groups in time for the peak in the number of females with sexual swellings, although they may have the competitive advantage over sub-mature males once they enter groups.

In terms of leaving, mature males remain in relatively high proportions for several months after the peak of females with sexual swellings, while numbers of sub-mature males decrease soon after the peak (Fig. 2c, d). This may reflect their competitive ability. Some females show sexual swellings after the peak, so it may be beneficial for relatively dominant mature males to remain in 
513

groups or enter groups after the peak. In contrast, mating opportunities for more subordinate submature males may decrease after the swelling peak because the number of mature males matches that of females with sexual swellings. The limited mating opportunities after the peak in females with sexual swellings may discourage sub-mature males from staying with or entering the group.

Male Spatial Positioning and Mate-guarding

The results of the spatial positioning were as predicted. The presence of females with sexual swellings positively affected the presence of mature males, but had no such effect on numbers of submature males, suggesting that mature males are able to successfully approach females with sexual swellings, while sub-mature males do so only occasionally even when they are in groups (Fig. 3; Table 4). Moreover, mature males mate-guarded females with sexual swellings more often than submature males. Many mature males followed females with sexual swellings, and none was followed by such females, indicating that mature males, not females with sexual swellings, intend to keep spatial proximity. These results suggest that mature males may have a mating advantage over submature males by mate-guarding females with sexual swellings effectively (Setchell et al. 2005), even in extremely large groups. Nevertheless, sub-mature males may also mate occasionally with females with sexual swellings, possibly siring some offspring, as observed in captivity (Setchell et al. 2005). We observed mature males in groups in all months (Table 1), suggesting that some mature males join and stay in groups even during the birth season. Our result for mature-male spatial positioning suggests that mature males are concentrated near females with sexual swellings during the birth season, when both are scarce (Fig. 3). Because we could not identify these mature males, we cannot conclude whether they visit groups only temporarily (Abernethy et al. 2002) or whether they live in groups throughout the year, as dominant males do under semi-free-ranging conditions and in released animals (Brockmeyer et al. 2015; Setchell and Dixson 2002; Setchell et al. 2006). Our data 
do show, however, that some mature males are present in groups even during the birth season, perhaps because they are able to increase their chances of siring offspring by mating with females swelling outside of the mating season. Long-term studies with direct observation are needed to clarify the residence, dominant status and sexual behaviour of these mature males.

\section{Limitations of the study}

We classified mature and sub-mature males based on their body length and other morphological traits, such as facial and genital coloration and development of the rump area. However, the development of secondary sexual traits in male mandrills depends on their social relationships, with subordinate mature males having supressed development, and body lengths also vary (Dixson 2015; Setchell and Dixson 2001; Wickings and Dixson 1992). It is, therefore, possible that we categorised some suppressed mature males as sub-mature males and some well-developed sub-mature males as mature males, potentially affecting our results. Measurement of male secondary sexual adornments will allow us to investigate the influx patterns of subordinate male mandrills, enhancing our understanding of primate alternative reproductive tactics (Setchell 2008; Setchell 2016).

\section{Conclusion and Perspectives}

We document variation in the number of mature and sub-mature males in mandrill groups, and differences in their spatial positioning in groups, suggesting that male mating tactics differ depending on their age and social status: subordinate sub-mature males join and leave groups in response to increases and decreases in the number of females with sexual swellings and approach them occasionally; dominant mature males enter groups around the peak in numbers of females with sexual swellings, stay for longer, and mate-guard females with sexual swellings; and some mature males are present in groups, and stay in the vicinity of females with sexual swellings, during the birth 
season. Thus, the mating season, out-of-season breeding and differences in male tactics all contribute to variation in the numbers of males in the group.

Our findings suggest adaptive explanations for the highly female-biased sex ratio of mandrill society. The monthly ratio of reproductive females to mature and sub-mature males varied between 1.9 and 4.9 seasonally (Table 1). Sex ratios were more female-biased during the birth season and approached the ratios of the number of reproductive females to the number of reproductive males in other African papionins during the mating season (agile mangabeys (Cercocebus galeritus agilis): 2.0 (Devreese et al. 2013); yellow baboons (Papio cynocephalus): 2.7 (Altmann et al. 1985); hamadryas baboons (P. hamadryas): 2.4 (Zinner et al. 2001); and geladas (Theropithecus gelada): 2.0 (Ohsawa 1979)), although the ratios of mandrills are far higher when only fully-grown males are considered. This suggests that the unusually female-biased sex ratio in mandrills derives from sex differences in gregariousness, which are more pronounced during the birth season. Female mandrills form the social core of groups (Bret et al. 2013), and their social relationships are highly matrilineal, with the dominance rank of daughters being immediately below their mothers, as is common in many cercopithecine primates (Dixson 2015; Setchell et al. 2008). Collective movements may be therefore adaptive for female mandrills. In contrast, most male mandrills leave groups when they are unlikely to mate. This may be because a solitary life allows males to avoid intensive male-male competition and injury (Setchell et al. 2006), to use habitats with preferred foods (Hamilton and Tilson 1982) and to reduce their travel distance and time (Slatkin and Hausfater 1976; Yamagiwa 1986). Because of their large bodies, living in groups may be more costly for male mandrills than for females in terms of within-group food competition and long-distance movements. The advantages of individual ranging may allow male mandrills to compensate for energy lost through male-male competition and group ranging, favouring the evolution of their extreme sexual dimorphism in body mass and canine size. 


\section{Acknowledgements}

We are deeply grateful to the Centre National de la Recherche Scientifique et Technologique

and the Agence Nationale des Parcs Nationaux in Gabon for permission to conduct this study. This

work would have been impossible without the help of colleagues: Yuji Takenoshita, Shiho Fujita,

Pierre Philippe Mbehang-Nguema, Chieko Ando, and all PROCOBHA researchers and staff members

gave us many advices and assists; Biviga Steven, Nzamba Victor, and all field assistants worked and

Tanaka and staff members of Kyoto City Zoo helped S.H. to master the mandrill age-sex class recognition; Hiroshi Himori, Hikari Ishijima, Aya Kokubu, and Takahiro Yamagishi assisted us in the

colleagues in Laboratory of Human Evolution Studies at Kyoto University for helpful discussions

and comments on the earlier manuscript. Francesco Bonadonna and three anonymous reviewers gave

Setchell and two anonymous reviewers greatly helped us to improve our manuscript. We thank

Editage (www.editage.jp) for the English language review. The study was funded by the Japan Society

\section{References}



Publishing.

611

612

613

614

615

616

617

618

619

Abernethy, K. A., White, L. J. T., \& Wickings, E. J. (2002). Hordes of mandrills (Mandrillus sphinx): extreme group size and seasonal male presence. Journal of Zoology, 258, 131-137.

Akaike, H. (1974). A new look at the statistical model identification. IEEE Transactions on Automatic Control, 19(6), 716-723.

Altmann, J., Hausfater, G., \& Altmann, S. A. (1985). Demography of Amboseli baboons, 1963-1983. American Journal of Primatology, 8(2), 113-125.

Borries, C. (2000). Male dispersal and mating season influxes in Hanuman langurs living in multimale groups. In P. M. Kappeler (Ed.), Primate Males: Causes and Consequences of Variation in Group Composition (pp. 146-158). Cambridge: Cambridge University Press.

Bret, C., Sueur, C., Ngoubangoye, B., Verrier, D., Deneubourg, J. L., \& Petit, O. (2013). Social structure of a semi-free ranging group of mandrills (Mandrillus sphinx): a social network analysis. PLOS One, 8(12), e83015.

Brockmeyer, T., Kappeler, P. M., Willaume, E., Benoit, L., Mboumba, S., \& Charpentier, M. J. (2015). Social organization and space use of a wild mandrill (Mandrillus sphinx) group. American Journal of Primatology, 77(10), 1036-1048.

Bronstrom, G. (2013). glmmML: generalized linear models with clustering. R package version 1.0. http://CRAN.R-project.org/package=glmmML.

Burnham, K. P., \& Anderson, D. R. (2002). Model selection and multimodel inference: a practical information-theoretic approach. New York: Springer.

Burnham, K. P., \& Anderson, D. R. (2004). Multimodel inference: understanding AIC and BIC in model selection. Sociological Methods \& Research, 33(2), 261-304.

Butynski, T. M. (1988). Guenon birth seasons and correlates with rainfall and food. In A. Gautier- 

of the African Guenons (pp. 284-322). Cambridge: Cambridge University Press.

635

636

637

Carnes, L. M., Nunn, C. L., \& Lewis, R. J. (2011). Effects of the distribution of female primates on the number of males. PLOS One, 6(5), e19853.

Chapman, C. A., \& Rothman, J. M. (2009). Within-species differences in primate social structure: evolution of plasticity and phylogenetic constraints. Primates, 50(1), 12-22.

Cords, M. (2000). The number of males in guenon groups. In P. M. Kappeler (Ed.), Primate Males: Causes and Consequences of Variation in Group Composition (pp. 84-96). Cambridge: Cambridge University Press.

Cords, M., Mitchell, B. J., Tsingalia, H. M., \& Rowell, T. E. (1986). Promiscuous mating among blue monkeys in the Kakamega Forest, Kenya. Ethology, 72(3), 214-226.

Devreese, L., Huynen, M. C., Stevens, J. M., \& Todd, A. (2013). Group size of a permanent large group of agile mangabeys (Cercocebus agilis) at Bai Hokou, Central African Republic. Folia Primatologica, 84(2), 67-73.

Di Bitetti, M. S., \& Janson, C. H. (2000). When will the stork arrive? Patterns of birth seasonality in neotropical primates. American Journal of Primatology, 50(2), 109-130.

Dixson, A. F. (2015). The mandrill: a case of extreme sexual selection. Cambridge: Cambridge University Press.

Dunbar, R. I. M. (2000). Male mating strategies: a modeling approach. In P. M. Kappeler (Ed.), Primate Males: Causes and Consequences of Variation in Group Composition (pp. 259-268). Cambridge: Cambridge University Press.

Hamilton, W. J., \& Tilson, R. L. (1982). Solitary male chacma baboons in a desert canyon. American Journal of Primatology, 2(2), 149-158.

Harding, R. S. O., \& Olson, D. K. (1986). Patterns of mating among male patas monkeys 
(Erythrocebus patas) in Kenya. American Journal of Primatology, 11(4), 343-358.

658

659

660

661

662

663

664

665

666

667

668

669

670

671

672

673

674

675

676

677

678

679

680

Henzi, S. P., \& Lawes, M. (1987). Breeding season influxes and the behaviour of adult male samango monkeys (Cercopithecus mitis albogularis). Folia Primatologica, 48(3-4), 125-136.

Holm, S. (1979). A simple sequentially rejective multiple test procedure. Scandinavian Journal of Statistics, 6(2), 65-70.

Hongo, S. (2014). New evidence from observations of progressions of mandrills (Mandrillus sphinx): a multilevel or non-nested society? Primates, 55(4), 473-481.

Hoshino, J. (1985). Feeding ecology of mandrills (Mandrillus sphinx) in Campo Animal Reserve, Cameroon. Primates, 26(3), 248-273.

Janson, C., \& Verdolin, J. (2005). Seasonality of primate births in relation to climate. In D. K. Brockman \& C. P. van Schaik (Eds.), Seasonality in Primates: Studies of Living and Extinct Human and Non-human Primates (pp. 307-350). Cambridge: Cambridge University Press.

Kappeler, P. M. (2000). Primate males: causes and consequences of variation in group composition. Cambridge: Cambridge University Press.

Kappeler, P. M., \& van Schaik, C. P. (2002). Evolution of primate social systems. International Journal of Primatology, 23(4), 707-740.

Kawazoe, T. (2015). Association patterns and affiliative relationships outside a troop in wild male Japanese macaques, Macaca fuscata, during the non-mating season. Behaviour, 153(1), 69-89.

Leigh, S. R., Setchell, J. M., \& Buchanan, L. S. (2005). Ontogenetic bases of canine dimorphism in anthropoid primates. American Journal of Physical Anthropology, 127(3), 296-311.

Mitani, J. C., Gros-Louis, J., \& Manson, J. H. (1996). Number of males in primate groups: comparative tests of competing hypotheses. American Journal of Primatology, 38(4), 315-332.

Nakagawa, N. (2000). Foraging energetics in patas monkeys (Erythrocebus patas) and tantalus monkeys (Cercopithecus aethiops tantalus): implications for reproductive seasonality. American 

Journal of Primatology, 52(4), 169-185.

682

683

684

685

686

687

688

689

690

691

692

693

694

695

696

697

698

699

Nakashima, Y. (2015). Inventorying medium- and large-sized mammals in the African lowland rainforest using camera trapping. Tropics, 23(4), 151-164.

Nunn, C. L. (1999). The number of males in primate social groups: a comparative test of the socioecological model. Behavioral Ecology and Sociobiology, 46(1), 1-13.

O'Brien, T. G., Kinnaird, M. F., \& Wibisono, H. T. (2003). Crouching tigers, hidden prey: Sumatran tiger and prey populations in a tropical forest landscape. Animal Conservation, 6(2), 131-139.

Ohsawa, H. (1979). The local gelada population and environment of the Gich area. In M. Kawai (Ed.), Ecological and Sociological Studies of Gelada Baboons (pp. 93-124). Tokyo: Kodansha.

Ohsawa, H. (2003). Long-term study of the social dynamics of patas monkeys (Erythrocebus patas): group male supplanting and changes to the multi-male situation. Primates, 44(2), 99-107.

R Core Team. (2015). R: a language and environment for statistical computing. R Foundation for Statistical Computing, Vienna, Austria. URL https://www.R-project.org/.

Ridley, M. (1986). The number of males in a primate group. Animal Behaviour, 34(6), 1848-1858.

Rogers, M. E., Abernethy, K. A., Fontaine, B., Wickings, E. J., White, L. J. T., \& Tutin, C. E. G. (1996). Ten days in the life of a mandrill horde in the Lopé Reserve, Gabon. American Journal of Primatology, 40(4), 297-313.

Setchell, J. M. (2003). Behavioural development in male mandrills (Mandrillus sphinx): puberty to adulthood. Behaviour, 140(8), 1053-1089.

Setchell, J. M. (2008). Alternative reproductive tactics in primates. In R. F. Oliveira, M. Taborsky \& H. J. Brockmann (Eds.), Alternative Reproductive Tactics : An Integrative Approach (pp. 373398). Cambridge, U.K.: Cambridge University Press.

Setchell, J. M. (2016). Sexual selection and the differences between the sexes in mandrills (Mandrillus sphinx). Yearbook of Physical Anthropology, 159, S105-S129. 
Setchell, J. M., Charpentier, M., \& Wickings, E. J. (2005). Mate guarding and paternity in mandrills: factors influencing alpha male monopoly. Animal Behaviour, 70(5), 1105-1120.

Setchell, J. M., \& Dixson, A. F. (2001). Arrested development of secondary sexual adornments in subordinate adult male mandrills (Mandrillus sphinx). American Journal of Physical Anthropology, 115(3), 245-252.

Setchell, J. M., \& Dixson, A. F. (2002). Developmental variables and dominance rank in adolescent male mandrills (Mandrillus sphinx). American Journal of Primatology, 56(1), 9-25.

Setchell, J. M., Kendal, J., \& Tyniec, P. (2011). Do non-human primates synchronise their menstrual cycles? A test in mandrills. Psychoneuroendocrinology, 36(1), 51-59

Setchell, J. M., Lee, P. C., Wickings, E. J., \& Dixson, A. F. (2001). Growth and ontogeny of sexual size dimorphism in the mandrill (Mandrillus sphinx). American Journal of Physical Anthropology, 115(4), 349-360.

Setchell, J. M., Lee, P. C., Wickings, E. J., \& Dixson, A. F. (2002). Reproductive parameters and maternal investment in mandrills (Mandrillus sphinx). International Journal of Primatology, 23(1), 51-68.

Setchell, J. M., Smith, T., Wickings, E. J., \& Knapp, L. A. (2008). Factors affecting fecal glucocorticoid levels in semi-free-ranging female mandrills (Mandrillus sphinx). American Journal of Primatology, 70(11), 1023-1032.

Setchell, J. M., \& Wickings, E. J. (2004). Social and seasonal influences on the reproductive cycle in female mandrills (Mandrillus sphinx). American Journal of Physical Anthropology, 125(1), 73 84.

Setchell, J. M., Wickings, E. J., \& Knapp, L. A. (2006). Life history in male mandrills (Mandrillus sphinx): physical development, dominance rank, and group association. American Journal of Physical Anthropology, 131(4), 498-510. 
Slatkin, M., \& Hausfater, G. (1976). A note on the activities of a solitary male baboon. Primates, 17(3), 311-322.

Struhsaker, T. T. (1977). Infanticide and social organization in the redtail monkey (Cercopithecus ascanius schmidti) in the Kibale Forest, Uganda. Zeitschrift für Tierpsychologie, 45(1), 75-84.

Takenoshita, Y., Ando, C., Iwata, Y., \& Yamagiwa, J. (2008). Fruit phenology of the great ape habitat in the Moukalaba-Doudou National Park, Gabon. African Study Monographs, Suppl 39, 23-39.

White, E. C., Dikangadissi, J.-T., Dimoto, E., Karesh, W. B., Kock, M. D., Abiaga, N. O., et al. (2010). Home-range use by a large horde of wild Mandrillus sphinx. International Journal of Primatology, 31(4), 627-645.

White, L. J. T. (1994). Biomass of rain forest mammals in the Lopé Reserve, Gabon. Journal of Animal Ecology, 63(3), 499-512.

Wickings, E. J., \& Dixson, A. F. (1992). Development from birth to sexual maturity in a semi-freeranging colony of mandrills (Mandrillus sphinx) in Gabon. Journal of Reproduction and Fertility, 95(1), 129-138.

Yamagiwa, J. (1986). Activity rhythm and the ranging of a solitary male mountain gorilla (Gorilla gorilla beringei). Primates, 27(3), 273-282.

Zinner, D., Peláez, F., \& Torkler, F. (2001). Group composition and adult sex-ratio of hamadryas baboons (Papio hamadryas hamadryas) in Central Eritrea. International Journal of Primatology, 22(3), 415-430. 